\title{
PROPIEDADE Y DIGNIDADE
}

\section{Pamela Alexandra Escudero Soliz ${ }^{1}$}

RESUMO: Como a propriedade é parte fundamental do modelo econômico de um Estado, a análise se concentra em revelar a preocupação sobre se a propriedade é um privilégio, um direito, uma garantia; se constitucionalmente e jurisprudencialmente está previsto a partir da dignidade do povo ou se tem limitações que não resolvam as desigualdades, estas são revistas e comparadas a partir dos diferentes instrumentos jurídicos dos países da Comunidade Andina: Bolívia, Colômbia, Equador e Peru.

PALAVRAS CHAVE: Constituição; direito; propriedade; limites; dignidade.

\section{PROPERTY AND DIGNITY}

SUMMARY: As property is a fundamental part of the economic model of a State, the analysis is focused on unraveling the concern of knowing if property is a privilege, a right, a guarantee; if constitutionally and jurisprudentially it is foreseen from the dignity of people or if it has limitations that do not resolve inequalities, these are reviewed and compared from the different legal instruments of the countries of the Andean Community: Bolivia, Colombia, Ecuador and Peru.

KEYWORDS: Constitution; law; property; limits; dignity.

\section{Introdução}

O retrato de uma mulher jovem que tem um velho sem-teto e sem sapatos, o valor da moeda menor que recebe um mendigo fora de uma igreja, o café de um velho obtido para suportar o frio, a ideia de segurança que as crianças têm trabalhando para trazer o pão para sua mãe, são bens que são observados em torno de importantes obras arquitetônicas do estado, em diferentes estágios da América Latina, estes são pertences de maior valor daqueles que estão vivendo desigualdade contra quem tem tudo: telhado, comida, saúde, educação, trabalho, propriedade.

Os pertences indicados são pensados em termos dos objetos e do valor que lhes é dado, pela adesão-apego de seus donos, seja por necessidade, urgência, amor ou doença. Como as pessoas são valiosas, a vida, a dignidade e a boa vida estão bem protegidos pelo

\footnotetext{
1 *Advogada dos Tribunais e Tribunais da República do Equador, pela Universidade Central do Equador, Mestre em Direito, com uma Menção em Direito Tributário e atual aluna do Programa de Doutorado em Direito, ambas na Universidade Andina Simón Bolívar, Sede Equador./Ele tem atuação profissional no setor público, prática gratuita e ensino universitário/pamxe23@ hotmail.com
} 
Estado, no entanto, as suas condições de mudar a direção do valor protegido em detrimento de pessoas sem propriedade, dignidade e boa vida. Neste contexto, o que é propriedade? Um teto, um espaço de terra, um lugar para morar, algo para ter, dinheiro para gastar, algo para administrar, em benefício ou detrimento de pessoas, quem diz o que é? Do que se trata?.

Propriedade e dignidade, reflete a ausência de dignidade na construção da propriedade como uma figura jurídica constitucional, também estuda os vários textos constitucionais dos quatro países da Comunidade Andina, que, apesar do progresso na proteção dos direitos sociais, ainda não conseguem a igualdade entre as pessoas, o que se reflite numa vida menos digna e mostra o esquecimento do valor dos seres humanos contra a construção da propriedade, seja como direito, valor, princípio ou garantia constitucional. Neste sentido, alguem pode pensar em propriedade a partir da dignidade das pessoas?

O objetivo deste estudo é apresentar o conceito de propriedade consagrado na doutrina de explicar se a propriedade foi concebida como direito constitucional, princípio ou garantia ou continua a responder à regulamentação do código civil, para o que é necessário analisar o desenvolvimento da propriedade e dignidade a partir das regras constitucionais da Bolívia (2009), Colômbia (1991), Equador (2008) e Peru (1993), que são revistas de acordo com as decisões judiciais dos órgãos constitucionais destes países, a fim de estabelecer características diferenciadoras da propriedade constitucional e de coincidir ou diferir se estiver relacionada com a dignidade humana.

Os métodos aplicados são dois: analíticos e comparativos, por meio dos quais a propriedade é identificada como conceito e figura jurídica constitucional, para analisá-la à luz da construção da constituição e extrair a coincidência ou a distância entre si e aplicação jurisprudencial em relação aos países membros da Comunidade Andina. No final, estabelecer elementos característicos ou diferenciadores entre um país e outro, tendo propriedade e dignidade como variáveis de identificação em cada caso.

\section{A propriedade é uma garantia, um princípio ou um privilégio?}

Um estudo acadêmico anterior (Escudero, 2013, p.28), com base no pensamento de Luigi Ferrajoli e Robert Alexi, eu relatou que uma garantia é uma garantia de que o Estado reconhece em favor dos seus cidadãos, que devem necessariamente ser consagrados -written na Constituição, "constitui o sistema de proteção destinado a garantir a validade e eficácia das liberdades e direitos fundamentais" (ESPARZA, 1995, p. 173). A qualidade da garantia é que 
ele pode ser viável (Ferrajoli 1999, p.63), enquanto que no pensamento de Robert Alexy "os princípios são comandos de otimização [...] são normas legais e quanto deve ser aplicado [ ...] não dão soluções decisivas, mas dão parâmetros de entendimento ". (2008, p.39-40).

Em seguida, o formulário de garantia textual expressa em quais áreas têm que trabalhar a norma jurídica tanto material como substancialmente, embora o princípio reforça a aplicação substancial de regra, se a garantia não pode ser realizável por si só. Nesse sentido, surge a seguinte questão, atualmente a propriedade é um princípio ou uma garantia?

O conceito contido na jurisprudência equatoriana indica que:

"O termo propriedade vem da palavra latina propietas", derivada, por sua vez propierum, que é o que pertence a uma pessoa ou é a sua própria, locução que vem da raiz "prope", o que significa fechar [...] certa unidade ou adesão, não física mas moral da coisa ou da pessoa. De acordo com as idéias naturais de propriedade, isso inclui todas as formas possíveis de agir sobre a coisa e todos os direitos possíveis que se originam dela [...] (CE, Constitutional Court, 2012).

Ou seja, a propriedade não foi definida como um objeto, mas como uma adesão moral de uma coisa a uma pessoa, como se as coisas pudessem aderir às pessoas como imãs. Se esta idéia for mantida, aquelas coisas que estão longe das pessoas a quem eles aderiram moralmente, não seriam consideradas pertences. Note que, nesta definição, não se refere a nenhum bem legal, seja princípio, direito ou garantia.

Este conceito de propriedade está ligado ao conceito de moralidade, que não dá abrigo, proteção ou dignidade às pessoas. Então a única adesão moral de uma pessoa a uma coisa, é chamada de propriedade? Eu diria que não, porque a propriedade como um direito legal protegido pelo Estado é regulado pelas normas de direitos humanos, pela Constituição e pelo direito civil (código civil). Em cada um desses instrumentos, foram definidas categorias de propriedade que podem ou não ser aplicáveis a todas as pessoas protegidas pelo Estado. Em outro sentido, o pensamento marxista leninista coletado por M. Rosental e P. Iudin, afirma que:

[...] a propriedade é determinada pelas formas de produção [...] Em oposição aos sábios burgueses que defendem o caráter imutável e eterno do princípio da propriedade privada, o Marxismo-Leninismo prova que a propriedade privada só apareceu em um determinada fase do desenvolvimento social [...] "(1985, p.249). 
Ou seja, a propriedade foi considerada como um princípio trabalhado no alvorecer dos meios de produção, não autônomo, mas está ligado a outro direito, o trabalho, então e aqueles que não têm trabalho, nem estão ligados a um meio de produção? Eles não têm acesso à propriedade privada, então eles não exercem seu direito, e um direito que não é exercido não existe, neste caso, alguns têm e outros não, então este direito não é para todos.

Note que a determinação da propriedade como um conceito não é específica, nem se refere a uma única coisa, está relacionada aos direitos humanos. Dentro deste contexto, acrescenta-se o fato de que, em tais conceitos, as desigualdades são destacadas. Assim, Montaigne ao se referir à desigualdade que existe entre nós - refere-se aos homens como várias pessoas - e indica algumas apreciações, que são mencionadas abaixo:

Todas as vantagens reais desfrutadas pelos príncipes são comuns aos homens de sorte média (apenas os deuses correspondem a cavalos alados e eles não têm um sonho diferente, ou um apetite diferente do nosso, eles não se armam com aço de melhor temperamento para o nosso, eles não cobrem a coroa nem do sol nem da chuva). (MONTAIGNE, 1985, p.332).

Se considerarmos que não há seres humanos melhores que os outros, por que as desigualdades são mantidas? e as vantagens, privilégios, direitos de uns são permitidos sobre os de outro, não é essa eleição outra forma de desigualdade, isto é, não é uma garantia do Estado que garanta o bem estar de todos os cidadãos, é a caso de propriedade que alguns acessam, outros não, e também tem limitações em detrimento daqueles que são considerados proprietários.

A esse respeito, Pierre-Joseph Proudhon argumenta que "[...] aqueles que hoje não possuem nada são proprietários em igualdade de condições com aqueles que possuem tudo; mas, ao invés de pedir que a propriedade fosse dividida, entre todos, ele pediu que fosse abolida para todos [...] (1975, p.52); neste caso, a propriedade é entendida como uma coisa que deve ser dividida entre todos ou ser abolida para evitar desigualdades, registradas na história.

Já, Alexis de Tocqueville (2005, p.5.) estabeleceu que "durante séculos, todas as antigas nações da Europa trabalham silenciosamente para destruir a desigualdade dentro dela", sem ter cumprido essa tarefa, porque como todos sabem, ainda hoje, a concentração da riqueza expressada em bens, dinheiro e ações está concentrada em uns poucos, enquanto a pobreza ea falta duma vida decente que tem pelo menos um teto para viver, sem que isso 
signifique o sacrifício e submissão do trabalho de toda a vida, é compartilhado entre muitos, algo ainda não foi resolvido.

A desigualdade é latente, a propriedade é o conceito que temos de repensar longe de compreender que a propriedade, riqueza, dignidade, qualidade de vida, tranquilidade são um privilégio e desgraça dos outros. Mais, quando as aspirações do Estado promulgaram a proteção dos direitos do povo, entre eles, a vida digna.

Encontrar-nos no início do século XXI, imerso no Estado Constitucional de Direitos e Justiça, que procura garantir os direitos de todas as pessoas que o compõem, bem como a igualdade, a não-discriminação, o bem-estar de todos que implica o acesso àliberdade, à propriedade e à dignidade do povo, por meio da compreensão de que não se trata do acúmulo de riquezas, não entendidas como aquelas:

Privilégios mais perigosos para aqueles que gostam deles são os privilégios em dinheiro, cuja extensão todos podem ver de relance, $[. .$.$] apenas um pequeno grupo de homens quer as honras$ e ter em vista a direção do Estado, mas eles ainda são menos quem não quer ser rico ". (TOCQVILLE: 2005, p.5.)

É por isso que me proponho a pensar na construção da propriedade estabelecendo limites e alcances que respeitem a dignidade das pessoas entendidas como o valor do ser humano e o sentido de sua própria existência, e daí a relação com outros direitos, é necessário dar conteúdo legal e constitucional à dignidade do povo, para que seja um ponto de partida nas aspirações de proteção do Estado. Essa forma contribuiria para a distribuição da riqueza, com o objetivo de fechar as brechas de desigualdade e evitar as afetações no sentido de valorizar as pessoas para si e não para suas posses.

Segundo Hobbes, a dignidade é a "avaliação pública de um homem que é o valor que lhe é conferido pelo Estado, o que os homens comumente chamam de dignidade". [...] “(2000: p.71)". Longe do entendimento de que uma pessoa deve ser apreciada por seus privilégios, e essa pessoa em posição de exercer sua liberdade, sem infortúnio, submeteu-o a uma vida de trabalho, à pobreza herdada ou ao abandono como destino.

Por isso é que, junto com repensar o conceito de propriedade, devemos repensar o conceito de dignidade, perguntando-nos: por que valorizamos o ser humano pelo que ele tem e não pelo que ele é em si mesmo? (MONTAIGNE, 1985); Entendendo que "mesmo que um homem se considere o mais valioso possível, seu verdadeiro valor não é outro senão aquele estimado por outros [...] a estimativa pública de um homem que é o valor conferido a ele pelo 
Estado é o que os homens geralmente chamam de dignidade. [...], (HOBBES, 2000: p.71). Nesse sentido, o Estado poderia receber os elementos necessários para promover a dignidade da propriedade, sem dar mais valor ao segundo. Então, dignidade e propriedade são direitos por meio dos quais uma vida digna pode ser alcançada? Para responder a esta pergunta, devemos rever a seguinte seção.

\section{Propriedade constitucional nos países da Comunidade Andina}

O objectivo deste ponto é o estudo da regulação da propriedade nas constituições da Bolívia, Colômbia, Equador e Peru, considerando que é a lei suprema e dentro dos limites das suas fronteiras, classificar os aspectos que regem a vida: social, econômica, política, cultural e ideológica de cada país.

Este estudo permite analisar como é regulada a propriedade, e saber o que o valor legal a ser dado à propriedade, entendendo que estes quatro países tem acima deles um passado histórico comum, bem como suas constituições são inspiradas pela Declaração Universal dos direitos humanos (1948: 17.1 e 2), sobre a propriedade oferece: "Toda pessoa tem direito à propriedade, individual e coletivamente" e "não pode ser arbitrariamente privado da sua propriedade". Como na Convenção Americana sobre Direitos Humanos (1969: 21.1 e 2), que afirma: "Toda pessoa tem direito ao uso e gozo de sua propriedade". Além disso, afirma que: "Ninguém pode ser privado de sua propriedade, exceto pelo pagamento de uma indenização justa".

Com as afirmações acima, é necessário rever a norma suprema que protege ou limita a propriedade e saber se existem semelhanças e diferenças, entre um país e outro, como segue:

\section{Tabela 1}

\section{Regulamentação constitucional da propriedade}

\begin{tabular}{|l|l|l|}
\hline No. & \multicolumn{1}{|c|}{ País } & \multicolumn{1}{c|}{ Constituição } \\
\hline 1 & Bolivia & $\begin{array}{l}\text { "I. Toda pessoa tem direito a propriedade privada individual ou coletiva, } \\
\text { desde que cumpra uma função social. } \\
\text { II. A propriedade privada é garantida desde que o uso dela não prejudique } \\
\text { o interesse coletivo. } \\
\text { III O direito de herdar herança é garantido ". } \\
\text { "O Estado reconhece, protege e garante a propriedade individual e } \\
\text { comunitária ou coletiva da terra, desde que cumpra uma função social ou } \\
\text { uma função econômica social, conforme apropriado." } \\
\text { "I. O descumprimento da função econômica social ou da posse da terra } \\
\text { será motivo para a reversão e a terra se tornará o domínio e a propriedade } \\
\text { do povo boliviano. " }\end{array}$ \\
\hline
\end{tabular}

CONPEDI LAW REVIEW | QUITO - EQUADOR | v. 4 | n. 2 | p. 215 - 233 | JUL - DEZ | 2018 


\begin{tabular}{|c|c|c|}
\hline 2 & Colombia & $\begin{array}{l}\text { "A propriedade privada e outros direitos adquiridos de acordo com as leis } \\
\text { civis são garantidos, o que não pode ser ignorado ou violado pelas leis } \\
\text { subsequentes. [...] Quando a aplicação de uma lei emitida por razões de } \\
\text { utilidade pública ou interesse social, em conflito com os direitos dos } \\
\text { indivíduos com a necessidade de reconhecimento, o interesse privado deve } \\
\text { ceder ao interesse público ou social. } \\
\text { A propriedade é uma função social que implica obrigaçães. Como tal, uma } \\
\text { função ecológica é inerente a ela. } \\
\text { O Estado protegerá e promoverá as formas associativas e solidárias de } \\
\text { propriedade. } \\
\text { Por razões de utilidade pública ou interesse social definido pelo legislador, } \\
\text { pode haver expropriação por decisão judicial e compensação prévia. Isso } \\
\text { será estabelecido consultando os interesses da comunidade e dos afetados. } \\
\text { Nos casos determinados pelo legislador, a referida desapropriação pode } \\
\text { ser antecipada por meios administrativos, sujeita a subsequente ação } \\
\text { contencioso-administrativa, inclusive no que diz respeito ao preço. }\end{array}$ \\
\hline 3 & Ecuador & $\begin{array}{l}\text { "As pessoas são reconhecidas e garantidas: } \\
\text { [...] O direito à propriedade em todas as suas formas, com } \\
\text { responsabilidade e função social e ambiental. O direito de acesso à } \\
\text { propriedade será efetivo com a adoção de políticas públicas, entre outras } \\
\text { medidas. [...] Tipos [...] "O Estado reconhece e garante o direito de } \\
\text { propriedade em suas formas públicas, privadas, comunitárias, estatais, } \\
\text { associativas, cooperativas e mistas, devendo cumprir sua função social e } \\
\text { ambiental". } \\
\text { "O Estado garantirá igualdade de direitos e oportunidades para mulheres e } \\
\text { homens no acesso à propriedade e na tomada de decisões para a } \\
\text { administração da sociedade conjugal". }\end{array}$ \\
\hline 4 & Perú & $\begin{array}{l}\text { "Todo mundo tem o direito: 16. Para propriedade e herança." } \\
\text { "O direito de propriedade é inviolável. O Estado garante isso. É exercido } \\
\text { em harmonia com o bem comum e dentro dos limites da lei. Ninguém } \\
\text { pode ser privado de sua propriedade se não, exclusivamente, por razões de } \\
\text { segurança nacional ou necessidade pública, declarado por lei, e após o } \\
\text { pagamento em dinheiro de compensação justificada que inclui a } \\
\text { compensação por eventuais danos. Existe ação perante o Poder Judiciário } \\
\text { para responder ao valor da propriedade que o Estado indicou no processo } \\
\text { de desapropriação". }\end{array}$ \\
\hline
\end{tabular}

Fonte: Constituições: (Bolívia, 2009, artigo 56); (Colômbia, 1991, art. 58); (Equador, 2008 art. 66.26) e (Peru, 1993, artigo 2), em vigor.

Elaboração própria

Das normas enunciadas, pode-se deduzir que, de fato, nos quatro países a propriedade é regulada, em suas diferentes formas e tipos. O interesse buscado por essa análise está relacionado à propriedade privada, considerando que ela está vinculada à dignidade das pessoas. Analisamos para ver em que medida cada Constituição dá valor a uma 
pessoa pelo valor de sua propriedade, em que medida tal acesso pode ser garantido e se é um direito ou um princípio.

A análise que se segue serve para compreender as palavras fornecidas para o estabelecimento das garantias, destacando aquelas que condicionam, limitam ou impedem o exercício real da propriedade como um direito, com o entendimento de que, embora a propriedade se destine a garantia do Estado, deve ser analisado em detalhe para compreender em que termos foi concebido.

Bolívia garante que todos têm o direito à propriedade privada, individual ou colectiva, desde que cumpre uma função social, ou seja, as condições de acesso da propriedade privada, o cumprimento da função social, sem indicar o que seria essa função social. Quanto à propriedade privada, estabelece que sempre garante que o uso feito não é prejudicial para o interesse coletivo, novamente indicando a palavra condicionado sempre implica que o Estado deve garantir o acesso à propriedade privada, valorizando o benefício ou prejuízo da comunidade, sem estabelecer o que seria entendido por lesão para a comunidade, o que poderia ser qualquer coisa.

Para esclarecer, a propriedade não é garantida de forma segura e de forma independente da individualidade de uma pessoa ou família, se não na sua avaliação ampla do sentido da comunidade. Em outras palavras, a propriedade privada é limitada pela própria Constituição, que por sua vez garante uma vida decente e igualdade perante a lei, os escopos da vida digna são individuais, igualdade perante a lei é individual, enquanto a propriedade privada construída a partir do sentido material, não.

Além disso, o mesmo corpo constitucional garante a propriedade individual e comunitária ou coletiva da terra, desde que cumpra uma função social ou uma função econômica social, conforme apropriado"(Bolívia,393). Esta seção nos chama a atenção, porque a propriedade é individual ou coletiva, está ligada à obrigação de que as propriedades cumpram sua função econômica, produtiva e social. O que acontece se uma pessoa tiver uma propriedade improdutiva economicamente? Só vive nele, sem exercer nenhuma atividade econômica, porque não tem profissão, não é empresário ou comerciante, dedica-se ao cuidado de familiares com habilidades especiais, a descoberta de talentos, entre outras atividades sem fins lucrativos.

O acesso a essa propriedade seria condicionado pela sensação de produtividade que falta, mesmo que não tenha sido definida no que ela é. Se a condição é satisfeita, sem verificar mais do que produtividade, neste caso, quem cuida de seus seres queridos, e ele mesmo, 
ficaria em aberto, assumindo que a necessidade de dar essa propriedade a quem o torná-lo produtivo e não para aqueles que precisam, neste caso, é urgente ter um contrapeso à dignidade, as pessoas não devem ser privadas de sua propriedade, só porque é improdutivo,uma medida de proteção deve ser garantida que lhes permita viver em a propriedade com dignidade. Em cada uma das disposições normativas relativas à propriedade individual, de uma forma ou de outra, foram estabelecidas condições para a sua conservação, em que a dignidade não aparece, como não é concebido, não é um direito ligado à propriedade.

Colômbia,exalta que a propriedade é garantida e que não pode ser desconhecida ou violada por leis subseqüentes. Uma particularidade deste regulamento é que ele prevê que: em caso de conflito entre os propósitos de utilidade pública ou interesse social, que resultem em conflito com os direitos dos indivíduos, esse interesse privado deve ceder ao interesse público ou social.

Sem um mínimo de direitos de propriedade com significado de dignidade humana que medeie entre o interesse do Estado e o cumprimento do interesse social por parte do indivíduo. Além disso, o corpo normativo aponta que a propriedade é uma função social que implica obrigações, isto é, não é um direito ou uma garantia, neste caso, está relacionada à função ecológica que deve ter, isto é, um princípio de conservação em benefício da natureza.

É importante indicar que, dos quatro países da região, a Constituição da Colômbia previu as condições de propriedade em caso de guerra, e indica que a necessidade de uma expropriação pode ser decretada pelo Governo Nacional sem compensação prévia, como na declaração de utilidade pública, por meio de um procedimento perante a autoridade competente, é oferecida compensação, entendida como o preço justo da propriedade expropriada.

Em caso de guerra, a compensação é dispensada, a expropriação temporária é declarada e, novamente, o que acontece com a dignidade do povo, duplamente violada pela guerra? A Constituição não menciona isso, apenas indica que a propriedade real só pode ser temporariamente ocupada, para atender às necessidades da guerra, ou para alocar seus produtos a ela. Mas quem sabe quando a guerra vai começar, quanto tempo dura, e quem pode pensar nos efeitos devastadores que geralmente deixa, a norma suprema deveria prever como a propriedade usada nesses casos seria compensada ou resolvida? de modo a não deixar a 
descoberto qualquer pessoa que esteja na condição de proprietário destituído à disposição do Estado.

No Equador, o Estado reconhece e garante o direito de propriedade em seus modos públicos, privados, comunitários, estatais, associativos, cooperativos, mistos, não usa palavras que impliquem uma condição, mas indica que o direito de propriedade deve obedecer sua função social e ambiental. Ao contrário da Constituição da Bolívia, neste caso não está condicionada ao exercício da função econômica da propriedade, no entanto, está condicionada à função social, sem especificar seu verdadeiro significado.

A norma suprema,indica que o direito de acesso à propriedade será efetivo com a adoção de políticas públicas, entre outras medidas que promovam a garantia de igualdade de direitos e oportunidades para mulheres e homens no acesso à propriedade e na tomada de decisão para a administração da sociedade conjugal, que, aliás, é uma sociedade que nasce do contrato de casamento, novamente sem especificar uma condição de acesso a que se refere nesta última seção tem a ver com o primeiro encontro o acordo de casamento.

Longe de ser cumprida ou não, a sociedade conjugal, como sociedade econômica, não parte da proteção da vida digna do núcleo familiar, indispensável ao exercício de qualquer acervo econômico, seja de propriedade ou de outro. Neste ponto, a propriedade é referida como um direito, ligado ao direito de liberdade.

No Peru, todos têm direito à propriedade e herança, o primeiro é inviolável e o Estado garante que é exercido em harmonia com o bem comum e dentro dos limites da lei. Ninguém pode ser privado de sua propriedade se não, exclusivamente, por razões de segurança nacional ou necessidade pública, declarado por lei, e após o pagamento em dinheiro de compensação justificada que inclui a compensação por eventuais danos.

Destaco a manifestação constitucional que refere que o direito à propriedade é exercido em harmonia com o bem comum. Assim, por um lado, o direito à propriedade é garantido, e, por outro, o bem comum também, mas não são ligados se não que são autônomos, independentes sem qualquer mídia condição; a palavra harmonia, usada para indicar que a propriedade privada é garantida, não torna como próprio esse direito.

No entanto, o bem comum, se opõe ao interesse da propriedade privada e entrar em conflito, é por isso que na relação: interesse comum, bem comum, Estado e propriedade privada, deve haver orçamentos constitucionais que protegam a dignidade das pessoas. Importante também, indicar que em caso de segurança nacional pode ser privado de propriedade, penso que esta máxima constitucional deve ser concluída, como o caso 
colombiano, especificando o que é a medida de compensação ou proteção de pessoas que são privadas de sua propriedade e aqueles que devem ser protegidos pelo mérito da dignidade.

A norma constitucional não menciona isso.A partir do estudo dos órgãos normativos constitucionais dos quatro países mencionados, infere-se que a propriedade é um direito garantido pelo Estado, mas condicionado ao exercício da função econômica, social ou social comum, e outros direitos, como liberdade, herança, casamento, em alguns casos planejados em tempo hábil e em outros vagamente.

Juntos, especificam que o Estado garante o direito à propriedade, mais está condicionado ao exercício da economia, em harmonia com o bem comum, ou exposto em caso de guerra e segurança nacional, nestes casos, o que faria o Estado? além de estabelecer uma compensação pelo preço justo, e pelo dano ou desconforto causado, esqueceu que, em termos de garantia de tratados internacionais e acordos sobre direitos humanos; às ações que se destinam a favor ou contra a propriedade, pois um direito constitucional deve acompanhar a garantia da dignidade humana, como um direito que deve ser respeitado mesmo fora das condições regulares.

Um mínimo de dignidade como um direito que não presume que com o dinheiro do preço justo o clima do povo seja resolvido. No espelho quebrado, as peças são semelhantes, mas todos eles não têm a mesma peça, a alma em que é realizada, a dignidade.

\section{Propriedade na jurisprudência andina}

Em um esforço para rever o relacionamento dos conceitos estabelecidos pela doutrina e rever a forma como são interpretadas as disposições constitucionais relativas ao direito de propriedade, ele vai para a fonte jurisprudencial reside nos órgãos constitucionais da Bolívia, Colômbia, Equador e Peru, para analisar quais são os critérios, conceitos ou normas que estão previstos para a resolução dos casos em que o referido direito é comprometido. Desta forma, podemos comparar como a previsão do mesmo direito pode ou não mudar de um Estado para outro, dentro da mesma região.

Antes de ligar para análise jurisprudencial é importante notar que o direito de propriedade também é considerado nos instrumentos internacionais, como indicado em linhas anteriores, e de acordo com essas inspirações algumas frases citá-los diretamente e outros vão apenas para a referência pretendida no Código Civil, como refere-se às afirmações 
jurisprudenciais relacionadas à propriedade que são consideradas importantes, para a análise do conceito de propriedade como direito constitucional e garantia.

\section{Tabela 2}

Propriedade nas mãos dos juízes

\begin{tabular}{|c|c|c|}
\hline No. & $\begin{array}{l}\text { Julgamento / } \\
\text { Tribunal/País }\end{array}$ & Conteúdo \\
\hline 1 & $\begin{array}{l}\text { Tribunal } \\
\text { Constitucional } \\
\text { Plurinacional da } \\
\text { Bolívia. Ficheiro: } \\
\text { 01051-2012-03-AAC) }\end{array}$ & $\begin{array}{l}\text { Os elementos constitutivos do conteúdo essencial do direito } \\
\text { de propriedade, nesse sentido, esse direito fundamental, cuja } \\
\text { gênese é encontrada não apenas no texto constitucional, mas } \\
\text { também no bloco convencionalidade, em seu núcleo duro são } \\
\text { identificados três elementos essenciais: a) O direito de uso; b) } \\
\text { O direito de gozo; e, c) O direito ao prazer. Da mesma forma, } \\
\text { esses três elementos têm um suporte axiológico que reforça } \\
\text { esse conteúdo essencial, baseado nos valores de liberdade, } \\
\text { igualdade, solidariedade e justiça. Por seu turno, também é } \\
\text { importante salientar que este núcleo essencial do direito de } \\
\text { propriedade fundamental gera obrigações negativas tanto } \\
\text { para o Estado quanto para os indivíduos privados que } \\
\text { resultam no seguinte: 1) Proibição de privação arbitrária de } \\
\text { propriedade; e, 2) Proibição de limitação arbitrária de } \\
\text { propriedade. }\end{array}$ \\
\hline 2 & $\begin{array}{l}\text { Tribunal } \\
\text { Constitucional } \\
\text { Colômbia Acórdão C- } \\
\text { 189/2006 }\end{array}$ & $\begin{array}{l}\text { Várias características são atribuídas ao direito de } \\
\text { propriedade, dentre as quais se destacam: (i) é um direito } \\
\text { integral, pois confere ao seu titular um amplo conjunto de } \\
\text { atribuições que ele pode exercer autonomamente dentro dos } \\
\text { limites impostos pela lei. legal e os direitos dos outros; (ii) É } \\
\text { um direito exclusivo na medida em que, como regra geral, o } \\
\text { proprietário pode se opor à interferência de um terceiro em } \\
\text { seu exercício; (iii) É um direito perpétuo na medida em que } \\
\text { persiste enquanto o bem sobre o qual o domínio é } \\
\text { incorporado persiste, e também, não se extingue - em } \\
\text { princípio - por sua falta de uso; (iv) é um direito autônomo, } \\
\text { uma vez que sua existência não depende da continuidade de } \\
\text { um direito principal; (V) é um direito irrevogável, no sentido } \\
\text { de reconhecer que a sua extinção ou transmissão geralmente } \\
\text { depende da vontade do seu proprietário e não a realização de } \\
\text { uma causa externa ou apenas querendo um terceiro e, } \\
\text { finalmente; (vi) É um direito real, considerando que é um } \\
\text { poder legal que é concedido sobre uma coisa, com o dever } \\
\text { correlativo de ser respeitado por todas as pessoas. } \\
\text { Compreende um voto contrário refere-se que, no contexto de } \\
\text { uma Constituição ecológica, a propriedade não é concebida } \\
\text { como um direito fundamental do absoluto, mas é um direito } \\
\text { sujeito a limpar e expressar limitações devido à função social } \\
\text { e ecológica a ser cumprida. }\end{array}$ \\
\hline 3 & $\begin{array}{l}\text { Tribunal } \\
\text { Constitucional } \\
\text { Equador. } \\
\text { Sentença n } \quad{ }^{\circ} 173, \\
\end{array}$ & $\begin{array}{l}\text { Como conceito, reflete o direito romano estabelecido "De } \\
\text { acordo com as idéias naturais de propriedade, o que inclui } \\
\text { todas as formas possíveis para agir sobre a coisa e todos os } \\
\text { direitos possíveis que ela, assim, dão origem ao direito de }\end{array}$ \\
\hline
\end{tabular}




\begin{tabular}{|c|c|c|}
\hline & 2012. & $\begin{array}{l}\text { uso, ou seja, , fazê-la servir a coisa para todos os usos } \\
\text { possíveis e recolher todos os frutos e produtos (ius utendi et } \\
\text { fruendi), certo livremente disponível (ius abundi, ou } \\
\text { disponendi ius), ou seja, a ação que tem o proprietário a agir } \\
\text { fisicamente sobre a coisa de acordo com a sua vontade, e } \\
\text { mudar a forma externa, disponha-a legalmente, renunciando- } \\
\text { a ou alienando-a ". } \\
\text { Em seguida, afirma que foi estabelecido no Código } \\
\text { Napoleônico, que é inspirado em nossa lei civil e prevê que } \\
\text { "o domínio que também é chamado de propriedade é o direito } \\
\text { real em uma coisa do corpo, para desfrutar e dispor dela, de } \\
\text { acordo com as disposições das leis e respeitando os direitos } \\
\text { dos outros, seja individual ou social. "Ela termina explicando } \\
\text { o processo de aperfeiçoamento do ato legal que implica o } \\
\text { exercício da propriedade, através da tradição. }\end{array}$ \\
\hline 4 & $\begin{array}{l}\text { Tribunal } \\
\text { Constitucional do } \\
\text { Peru. Frase EXP. No. } \\
\text { 03258-2010-PA / TC }\end{array}$ & $\begin{array}{l}\text { O direito à propriedade é um direito fundamental que está } \\
\text { intimamente relacionado com a liberdade pessoal, porque } \\
\text { através dela expressa a liberdade econômica que cada pessoa } \\
\text { tem no Estado social e democrático de direito. O direito de } \\
\text { propriedade garante a existência e a integridade da } \\
\text { propriedade (corpórea ou incorpórea) para o proprietário, } \\
\text { bem como a participação do proprietário na organização e o } \\
\text { desenvolvimento de um sistema econômico-social. Portanto, } \\
\text { o "direito de propriedade é inviolável" e o "Estado garante". } \\
\text { O direito de propriedade autoriza seu proprietário a usá-lo, } \\
\text { apreciá-lo, explorá-lo e descartá-lo, desde que, por meio de } \\
\text { seu uso, a função social adequada seja realizada. (...) o direito } \\
\text { de propriedade é "exercido em harmonia com o bem } \\
\text { comum". E não apenas isso; Além disso, inclui o direito de } \\
\text { defender a propriedade contra qualquer ato que tenha efeitos } \\
\text { de privação sobre a integridade da propriedade protegida. } \\
\text { O Tribunal indicou isso na sentença proferida no processo no } \\
\text { 05614-2007-PA / TC, o direito de propriedade caracteriza-se, } \\
\text { entre outras coisas, por ser: a) um pleno direito, no sentido } \\
\text { em que o confere ao seu dono um vasto conjunto de poderes } \\
\text { que podem ser exercidos de forma autónoma dentro dos } \\
\text { limites impostos pelo sistema legal e pelos direitos dos } \\
\text { outros; e, b) o direito irrevogável, no sentido de reconhecer } \\
\text { que a sua extinção ou transmissão depende do livre arbítrio } \\
\text { do titular e não realizando uma causa estranha ou apenas } \\
\text { querendo um terceiro, exceto conforme expressamente } \\
\text { previsto na Constituição Política. }\end{array}$ \\
\hline
\end{tabular}

Fonte: Sentenças dos órgãos constitucionais da Bolívia, Colômbia, Equador e Peru.

Elaboração própria 
De acordo com as afirmações jurisprudenciais, existem elementos comuns e diferentes que podem ser especificados sobre as ações dos juízes de cada órgão constitucional e, de acordo com a jurisprudência anteriormente estabelecida, definiu o que é propriedade do Estado Constitucional, o que garante em certa medida acesso à propriedade. Os elementos comuns em três sentenças são: que antes de definir o que é a propriedade, características e elementos são identificados para indicar se a propriedade está protegida ou limitada.

Bolívia, identifica três elementos essenciais: a) $\mathrm{O}$ direito de uso; b) $\mathrm{O}$ direito de gozo; e, c) O direito ao prazer. Além disso, estes três elementos são baseados nos valores da liberdade, igualdade, solidariedade e justiça. Note-se que a norma constitucional boliviana chama valores para o que no Equador é chamado de direitos. Além disso, enfatiza que este modo de prever a propriedade gera obrigações negativas para o Estado e para os indivíduos, tais como: a proibição da privação arbitrária de propriedade; e a proibição de limitação arbitrária de propriedade. Na sentença eles são fatores negativos para o Estado e para os indivíduos, entretanto, essas proibições respeitam o conceito de propriedade inerente da pessoa, pois para exercer arbitrariedade ou limitar deveria ter considerado os casos em que tais condições poderiam ocorrer, tal o caso de guerra ou segurança nacional considerado nas instituições da Colômbia e do Peru, respectivamente.

No caso da Colômbia, o juiz constitucional indica que o direito de propriedade tem as seguintes seis características: (i) É um direito pleno porque pode ser exercido de forma autônoma de acordo com o sistema legal e os direitos de outros; (ii) É um direito exclusivo porque o proprietário pode se opor à interferência de um terceiro em seu exercício; (iii) É um direito perpétuo, dura enquanto o bem em que o domínio é incorporado persista, e também, não se extingue por falta de uso; (iv) é um direito autônomo não depende da continuidade de um direito principal; (v) É um direito irrevogável, depende da própria vontade do seu dono e não da realização de uma causa estranha ou apenas da vontade de um terceiro, e finalmente; (vi) É um direito real porque o poder legal é concedido sobre uma coisa, com o dever correlativo de ser respeitado por todas as pessoas, (Tribunal Constitucional do CO, 2006).

As características claramente referidas, diferem dos elementos enunciados no caso da Bolívia, e do Equador, como será visto abaixo, como eles indicam a descrição da propriedade, como um objeto de direito, que não depende de outros a existir, -lo que foi indicado, que não, porque nos casos depende de outros direitos - que não se extingue por sua falta de uso, depende da vontade do dono, e de todos os indicados acima. Note-se que, diferentemente do caso equatoriano e boliviano, esse direito é autônomo e não se refere nem à 
liberdade nem a uma vida digna. É importante indicar como semelhança, e isso devido ao voto salvo do julgamento analisado que refere que a propriedade não é concebida como um direito fundamental de natureza absoluta, mas constitui um direito sujeito a limitações claras e expressas devido à função social e ecológica, que devem obedecer, de acordo com o contexto de uma Constituição ecológica.

Na revisão do acórdão do Tribunal Constitucional do Equador, o significado ou conceito de propriedade do domínio de design para o que o juiz chamado a propriedade, e indica que é um direito real que pesa sobre uma coisa corpórea a desfrutar e dispor dela, de acordo com as disposições das leis e respeitando os direitos dos outros, seja individual ou social. Neste caso há elementos ou características da propriedade são identificados, mais do que um relato histórico de como os direitos de propriedade inspirados pelo pensamento francês vem ao Equador é feito, e está prevista no Código Civil, conforme indicado nas linhas anteriores como um direito real, que deriva do direito à liberdade e que é garantido pela Constituição, desde que cumprida sua função social, semelhante ao caso boliviano. Em termos de propriedade, o âmbito do direito civil são sólidos e permanecem inalteradas em relação ao tempo e ao espírito do Estado constitucional, porque em essência, continua a referir o seu direito civil conteúdo material e não constitucional.

No Peru, o Tribunal Constitucional define propriedade com as seguintes afirmações: a) direito pleno, pois confere ao seu titular as atribuições que pode exercer de forma autônoma, respeitando o ordenamento jurídico e os direitos dos demais; e, b) como direito irrevogável, na medida em que depender da vontade do próprio dono e não da realização de uma causa estranha ou da vontade exclusiva de um terceiro, salvo as exceções expressamente previstas na Constituição Política, para este caso serian as expropriações temporárias por causa da segurança nacional.

Como foi referido no contexto jurisprudencial de cada país, existem semelhanças e diferenças que permitem reconhecer, a nível regional, a propriedade privada de um lado como um direito autónomo e, por outro, relacionado com o direito de liberdade, solidariedade, embora não como o direito à igualdade, porque só foi enunciado no caso boliviano e como um valor.

De acordo com as limitações referidas pela norma suprema, é um direito que deve garantir a Constituição de um Estado, mas não é um direito absoluto, como no caso da Colômbia e do Peru as condições desfavoráveis, em caso de guerra ou por razões de segurança nacional, 
pode ser quebrada com a inviolabilidade da propriedade e até mesmo temporariamente, o Estado poderia dispor da propriedade privada dos cidadãos, de acordo com seus interesses nacionais.

É importante notar que, em todos os conceitos, elementos, características, descrições, análise, interpretação e reiterações estabelecidos pelos juízes, todos se referem à propriedade com base no objeto que é impregnado com tal valor jurídico, em nenhum dos casos tem Trata-se de uma propriedade tratada de solidariedade ou igualdade na compreensão de que todas as pessoas podem ter o direito à propriedade, salvaguardar sua dignidade e suas vidas. Nem se referiram a esta dignidade pode ser um limite para o poder do estado, a respeitar não só a propriedade, mas a dignidade das pessoas, que, em caso de situações de guerra ou de segurança nacional, não só deve reconhecer a valor do preço justo do imóvel ou dispensá-lo devido à gravidade das circunstâncias, mas este direito deve ser garantido de acordo com o valor e a dignidade da pessoa sobre as coisas.

Respeitando a teoria da propriedade diz respeito ao uso, gozo e disponibilidade de coisas, exercido como um direito, desde que cumpra a função social ou económica, deve se pensar em igualdade, solidariedade e dignidade das pessoas, não só no objeto, mas no sujeito que o possui ou deseja possuí-lo, e estabelece uma ordem de disponibilidade que medeia entre a concentração da riqueza e a pobreza, que estabelece parâmetros de dignidade que permitam uma vida digna.

\section{Conclusões}

1. Em termos de propriedade privada, o âmbito do direito civil é sólido e permanece inalterado em relação ao tempo e às aspirações do Estado Constitucional, porque o seu conteúdo material continua a referir-se ao direito civil e não ao direito constitucional.

2. A propriedade como um direito, não é absoluta, nem individual, está ligada ao cumprimento de condições de diferentes tipos, bem como a outros direitos, como o caso dos direitos de liberdade, casamento e herança.

3. A propriedade privada concebida como direito e garantia que estabeleça as condições adequadas para o desenvolvimento das pessoas, para a proteção de sua dignidade, não deve ser constituída como meio de produção ou privilégio de quem trabalha, quem herda, casar ou eles cumprem um propósito social ou econômico. Deve ser garantido, para garantir a igualdade social e a dignidade do povo. 
4. Apesar de pertencerem ao mesmo passado histórico, os quatro países mencionados neste documento não possuem um direito de propriedade que esteja relacionado à dignidade do povo, ao contrário, sua função econômica, ecológica ou social é registrada.

5. O Estado promove a propriedade privada ou individual do bem comum, estabelecendo certas condições ou limitações, sem considerar um parâmetro necessário de dignidade, que não seja sacrificado contra os interesses do Estado, em qualquer caso.

6. A propriedade na Colômbia e no Peru, respectivamente, é limitada e constitucionalmente condicionada a certas circunstâncias políticas: guerra e segurança nacional, sem meios de compensação pela violação ou restrição deste direito, além do preço da propriedade.

7. Se o direito de propriedade estiver relacionado aos direitos humanos, ele deve ser universal, acessível, distribuído equitativamente e não condicionado. A apropriação poderia ser concebida a partir da igualdade social, da solidariedade e da dignidade do povo, estabelecer critérios que coloquem as lacunas existentes entre a riqueza e a pobreza, critério que, em primeiro lugar, seria a dignidade humana.

8. As limitações e condições dos direitos de propriedade desigualdades adotivos a partir do próprio estado, para mudar, não é razoável imaginar que, como quantificado, valor e distribuir dívidas estaduais para cada recém-nascido, da mesma forma, que é distribuído propriedade do Estado, no momento do nascimento, para adquirir identidade, cidadania e ser titulares de deveres, direitos e garantias do Estado, um montante que representa a medida de segurança que seria suficiente para começar uma vida decente é tratada, quantidade que é projetado no futuro em direção a um plano nacional.

9. Propriedade e dignidade ao nascer, à vida, à trajetória, e não ao túmulo, ao morrer, como acontece com o direito de herança, que, incidentalmente, surge da morte de uma pessoa. Essa premissa envolveria a regulação de outros aspectos do próprio modelo de Estado, tais como: modelo de desenvolvimento econômico, planejamento familiar, equidade e redistribuição de riqueza.

\section{Bibliografia}


ALEXY, ROBERT, «El derecho general de libertad», en Teoría de los derechos fundamentales, Madrid, Centro de Estudios Constitucionales, 1997, citado por Ramiro Ávila Santamaría, en Constitución del 2008 en el contexto andino análisis de la doctrina y el derecho comparado, Quito, Ministerio de Justicia, Derechos Humanos y Cultos, 2008.

ESCUDERO SOLIZ, PAMELA, De la Prueba Desafío a la Prueba Administrativa Tributaria, Serie Magister 155, Quito, Corporación Editora Nacional y Universidad Andina Simón Bolívar, 2013.

ESPARZA LEIBAR, IÑAKI, El Principio del Debido Proceso, Barcelona, José María Bosch Editor S.A., 1995.

FERRAJOLI, LUIGI, Derechos y Garantías la Ley del más débil, Madrid, Editorial Trotta 1999.

HOBBES, THOMAS, Leviatán o la materia, forma y poder de una república, eclesiástica y civil, México, Fondo de Cultura Económica, 2000.

MONTAIGNE, MICHAEL, Ensayos I, Edición de María Dolores Picazo, Traducción de Almudena Montojo, Madrid, Cátedra Letras Universales, 1985.

PROUDHON, PIERRE-JOSEPH, Historia del Pensamiento ¿Qué es la propiedad? Traducción de Rafael García, Barcelona, Ediciones Orbis, 1975.

ROSENTAL M. Y IUDIN. P., Diccionario filosófico marxista leninista, traducción directa del ruso, por M.B. Dalmacio, s/c, Ediciones Amauta, 1985.

TOCQUEVILlE, ALEXIS, Discursos y Escritos Políticos, Madrid, Centro de Estudios Políticos Constitucionales, 2005.

\section{Fontes normativas}

1. Bolívia, Constituição do Estado Plurinacional da Bolívia, 2009, artigo 410, http://bolivia.infoleyes.com/shownorm.php?id=469 [28/12/2011 4:30:59 PM]

2. Colômbia, Constituição Política da Colômbia, 2016, Artigo 4, Edição Especial preparada pelo Conselho Superior da Corte Constitucional do Centro Judiciário de Documentação Judicial - CENDOJ Biblioteca Enrique Low Murtra - BELM, http://www.corteconstitucional.gov.co/inicio/Constitucion\%20politica\%2 Constituição 0de\% 20Colombia.pdf

3. Equador, Constituição da República do Equador, 2008, artigo 424, Registro Oficial 449 de 20 de outubro de 2008.

4. Peru, Constituição Política do Peru, 1993, artigo 51,

http://www.constitucionpoliticadelperu.com/

\section{Fontes Jurisprudenciais}

5. Bolívia, Tribunal Constitucional Plurinacional da Bolívia, Arquivo "Julgamento" 01051-2012-03-AAC, 5 de setembro de 2012,

http://spij.minjus.gob.pe/content/jurisprudencia_extranjera/repositorio/2016/09/ Bolivia / Sentencia0998-2012. pdf.

6. Colômbia, Corte Constitucional da Colômbia, "Sentença" C-189/06, sem data, arquivo fornecido no material do assunto ensinado no assunto: Garantias constitucionais de propriedade e livre iniciativa econômica. 
7. Equador, Tribunal Constitucional do Equador, "Julgamento" N.0173 no Processo $\mathrm{n}^{\circ}$ $0785-$

10EP, 26 de abril de 2012.

8. Peru, Tribunal Constitucional do Peru, "Julgamento" EXP. No. 03258-2010-PA / TC, 20 de Abril de http://www.tc.gob.pe/jurisprudencia/2011/03258-2010-AA.html 